\title{
No surgeon is an island, no echo stands alone
}

\author{
Martin Riegler
}

(C) Springer-Verlag GmbH Austria, part of Springer Nature 2019

Dear reader,

Welcome to this issue of European Surgery. YOUR eyes may catch what you like. YOUR choice may echo the taste of your mind. Wherever you are, whatever emotion you share, whomsoever you owe respect, attention and love: science is all about YOU. The highly motivated group of authors, co-authors, reviewers and the publisher are to be congratulated for having chosen, designed and orchestrated this welltuned spectrum of beautiful papers. In line with the aims, scopes and focus of European Surgery the publications include themes, topics and stories from the fields of minimally invasive surgery, liver shark delivery of cysts, pancreas pancakes, rolls and tissues of wave-like oncologic disease management for interdisciplinary diagnosis including the treatment of conditions that definitely impair the quality of life, productivity and well-being of humans in Europe and abroad, since, as a matter of fact, any long sentence will find its end. Thus, the scientific stories definitely express what should be clear for everyone reading those lines: no surgeon is an island, no echo stands alone. Therefore, let us understand: surgery means team work. Surgery implies team work. It is not enough to talk about it. It is not enough to refer to it. YOU have to live it. YOU have to teach it. No educator is an island. Stay away from miserable politics, hypocrites, greed, hate, envy, emotional thunder and war. Look out for those things we have in common, search for those qualities we share and we all need: respect, understanding, fairness and honesty. As long as you all can do so, the better you may design the character, ambitions and motivations of your team, working place

\section{Doz. Dr. M. Riegler $(\bowtie)$}

Reflux Medical, Mariannengasse 10/9, 1090 Vienna, Austria martin.riegler@refluxmedical.com and outcomes of your clinical, scientific and PRIVATE life. Statistics fail, in as much the translator escaped $(p<0.001)$. Surgeons should always consider the full spectrum of pros and cons, advantages and disadvantages of a given state of affairs. Taken together, any coin forms two sides of a matter, the essence of which is hidden deep within (curiosity?) and awaits our attention, exploration and discovery.

Believe it or not, reality is as it is, and what it means to us, what reality implies, denotes and indicates for us, echoes the truth-and this truth equals our current state of mood, atmosphere, temper and mindset. Taken together, YOU, dear reader, irrespective of whether you are aware of it or not: YOU are not an island, YOU do not echo alone. YOU are not as important as you may think. YOU may gain importance by the support, fair treatment and motivation of others. Or let us put it the other way round: space time, electromagnetic, strong and weak nuclear forces are the infielders of our home run! Well taken! Let us proceed. Every one of us houses spiritual energy of immense value and quality. However, routine life frequently prevents us from gaining the positive vibrations. As a consequence we usually have to deal with and resist the power, force and influence of energies that are directed against us, against our freedom and health. As such, you may share the destiny of your patients and become a victim of your desires, expectations and desperations. At this point you may ask: who do I copy, who do I paste into my work, to whom do I sell? Am I selling my body and soul? To whom? By whom am I sold? Am I at work or am I the executor of others? Are we ready for a distinct final count down, here in the academies and abroad? Simply spoken: are we allowed to leave the home base?

If you mind those lines, feel free to skip this editorial. Irrespective of whether you read it or not, the themes, topics, motives and tunes outlined in this 


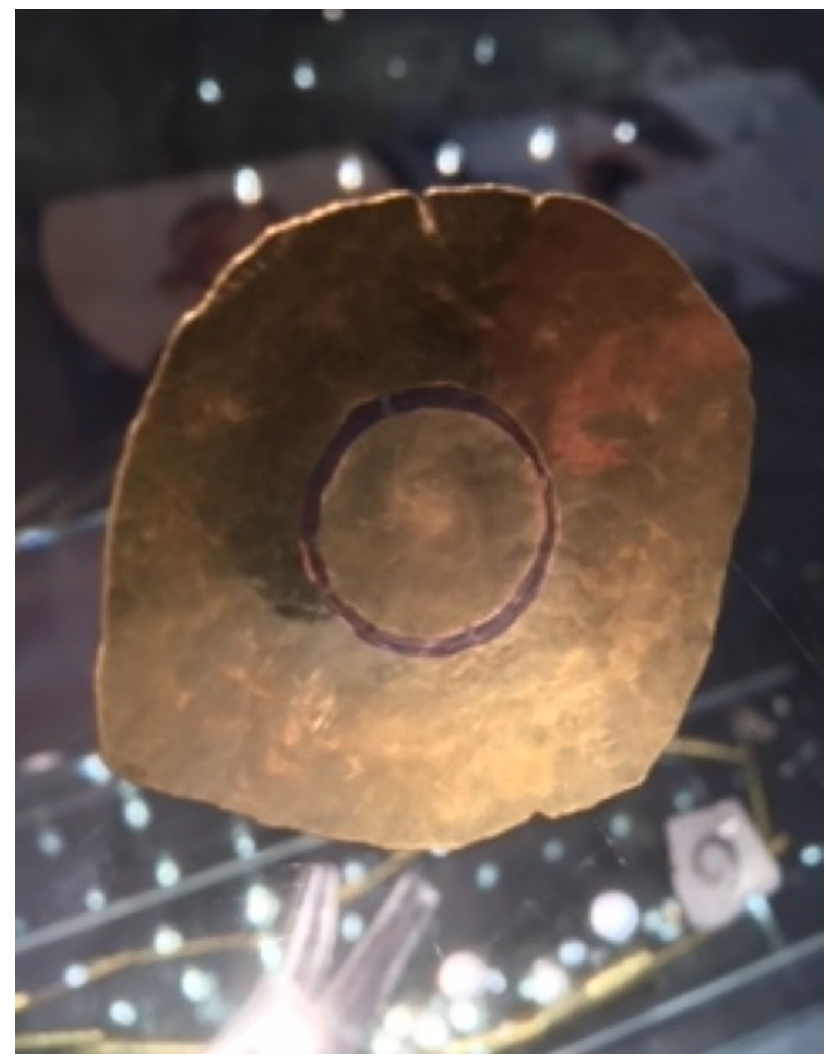

Fig. 1 The jewellery mirrors the idea that time and space orchestrate the background of our perceptions, as outlined in the text. Image obtained at the Slavik Gallery, Downtown Vienna, Austria, EU

editorial are about nothing else but you; they deal with nothing else but YOU. Those lines are exclusively about YOU. Those lines push you into the central, exclusive focus and interest of the author. How often does it happen that you are allowed to be the beloved focus of someone else's reasoning, motivation, attention and respect? Maybe you are open to look into yourself, sense yourself and try to understand who and what you are. Otherwise you may be forced to repeat the mistakes of our ancestors, who stopped listening and learning; you may be prone to repeat history, the consequences of power games and despotism. Maybe you allow yourself to open your mind for your individual dreamland, where hate, greed, envy and mischief are replaced by outbalanced fairness of respect, understanding and open-minded conduct of reasoning. Tune yourself and be strong, successful and positive. It is all about YOU. Thus, dear reader, I kindly invite you to follow me for this immediate journey. Our present journey visits the fascinating islands within the lower end of the oesophagus, OUR gullet, where it all comes from, reaches out to faroff galaxies, stars and ancient cultures and seeks the legacies of a lost civilisation, i.e. our ancestors, with whom we share fundamental amounts of genetic information, behaviour and habits [1-10]. Time seems to vanish, space seems to trace back the invisible lights to the origins of our perceptions (Fig. 1). Here we go for the meal, where silicon valley shrines use to serve us brilliant black holes and side fish fidelity for waterman wave function factory: the show must go on, as the eclipse centres the fields of the zodiacs.

\section{The matrix of emotions}

In the recent issues of European Surgery we aimed to address the extent to which myth, surgery and science share a common underlying conceptional character, emotional stream, quality, mechanism and may create a distinct mindset for the conduct of reasoning. As such, we figured out that myth and surgery work in a comparable manner: both myth and surgery act by the translation of images/perceptions into treatable signs [1-5]. In addition, myth and surgical science serve to save knowledge and information for the next generations of our civilisation and medicine. The translation of images into treatable signs works by the use of so-called codes [6-10]. Codes represent systems of connotations with a very specific meaning and define the communication symbols and signs of a given culture, group, or society and support the development of a distinct mindset. As such, codes underlie the language of our semiotic process of communication. Language and other code-forming types of sensual expression (music, dancing, architecture, arts, grafts, paintings, food, taste, smell, fashion, politics, money, etc.) allow us to treat signs, to diagnose, react, interact, treat and follow-up. Meaning develops as the result of perception-based experience and understanding. Over time perceptions teach their significance, their meaning, their role and essence to us, to a community, to a defined group of people. Therefore, the translation of myth, images and symbols into treatable signs is related to the codes (Fig. 2). Codes simply create the matrix of translation, the rules of decoding, the background for the inventions of our language. Knowing the code, we are enabled to translate an image into a treatable sign. For example: based on the code of clinical science, pain and tenderness within the lower right quadrant of the abdomen may indicate the presence (differential diagnosis) of appendicitis, colitis, right kidney, right ovary disease, etc. The code is taught at medical school and results from the ongoing process of semiotic analysis (anatomy, pathology, physiology, gender medicine) and is maintained within the complex system of medical knowledge and academic science. Without knowledge of the code, the sign would be without use for the recognition of a disease. The appendicitis example nicely demonstrates the extent to which myth and clinical diagnosis operate in a comparable manner: both translate images into treatable signs. Most interestingly, the same is true and happens within the outstanding, fundamental, global, continuous, poly-semiotic oligo-chain reactions providing internet and social media (facebook, twitter, 


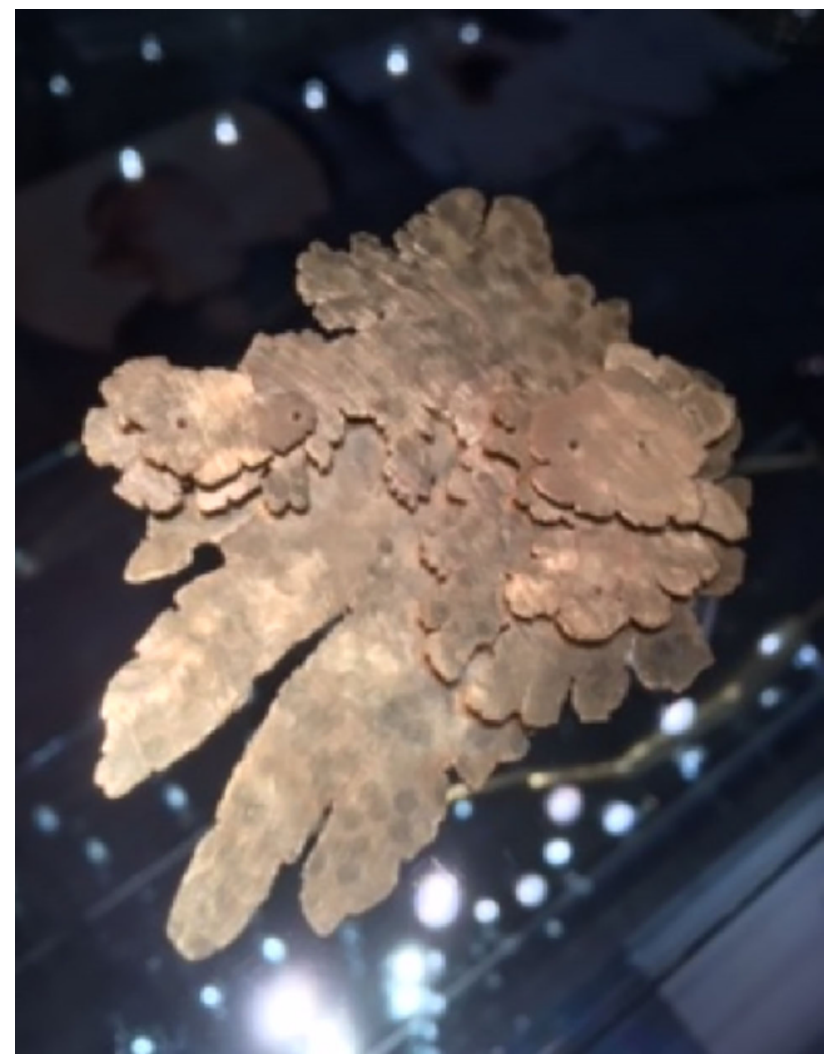

Fig. 2 The jewellery models the idea that the interpretation of perceptions follows the code-based translation of images into treatable signs, as outlined in the text. Jewellery aims to attach the force, brightness and fascination of cosmic galaxies to the surface of the human body. Image obtained at the Slavik Gallery, Downtown Vienna, Austria, EU

instagram). Beyond all orchestrates the complexity of the continuous stream of reality. Based on your current state of mood, temper and atmosphere, reality gains a specific meaning, i.e. positive, negative, motivating, inhibiting, concerned, light, easy, cosy, etc. And this specific meaning/atmosphere turns out to model the truth. Taken together, our approximation teaches us that reality, truth and meaning are kept in tune by our individual state of mood, temper and momentary atmosphere. We are the sudden products of our well-tempered emotional matrix. At this point language seems to have reached the limits of its expression and alternative sounds of translation reach out for our unspoken sensations, desires, dreams and fantasies. Therefore, patient histories always offer specific moments, symptoms and signs that are difficult to understand, even for an experienced surgeon.

\section{Human family history: well taken}

In line with the great Italian thinker and outstanding academic poet, the late Umberto Eco, who profoundly contributed to semiotics, codes may develop, change, alter, jam, interact, arise, flux and fluctuate within the process of myth-forming and foster the translation of images into treatable signs. During the history of a given population the connection between signs and codes may vanish, the meanings may get lost and the ability for translation ceases [6-10]. As a consequence we observe various forms of culture-forming collective memory, which somehow senses and transfers a lost, hidden information and knowledge. For example, Babylonian linguistic confusion develops and effectively hides the underlying significance, meaning and code-based language of a system of signs. Could it be that the image of the Babylonian linguistic confusion does not refer to the loss of a spoken language like a given Sumerian, Egyptian, Cretan, Babylonian, Indus valley, Danube valley, Mississippi valley cultural dialect? Could it be that people had simply lost their understanding for astronomy, physics, natural behaviour: the understanding of the language spoken by the cosmic clock of the zodiac signs, the sun, the moon, the stars, which is essential and fundamental for the seasonal stellar orientation of time, space and human life [6-10]. Thousands of years ago civilisations erected zodiac clocks around our beautiful globe [6-10], including Stonehenge, Malta, Vinca, Gobekli Tepe, Carnac, Gizeh, Tiwanaku, Teotihuacan, Palenque, Angkor Wat, Easter Island, the Amazon, and the Mississippi valley etc. Given the fact that people were somehow cut off from the heavens and thus might have lost their polarised orientation, they were presumably considered to have been subsequently prone to mischief, violence, vulnerability, warfare, insecurity and disaster, a scenario which is remembered at least in part in the form of flood myths all over our beautiful globe. At this point, due to the loss of the original code (roots music), a civilisation could have lost its capacity to understand the full spectrum of accurate scientific information required for welfare and provided within a myth (skin, bone and dreadlocks). Science becomes myth if the code for its decoding has been lost (PUB MED: "Lessons learnt from the gastric cardia”) [1-5]. It prevents us from receiving important information (logos). Devoid of the code myth-telling simply appears as pure fantasy without any relation to the so-called "realistic" or "real" world (physics). As a consequence, a legacy of valuable information may get lost to us and prevents us from gaining access to these forms of wisdom (morals), knowledge, mastery, outlook and fate (ethics). In line with this notion, the work of Graham Hancock suggests that the ancient myths incorporate the traces of a lost civilisation that was wiped out during a comet-induced global cataclysm approximately 11,000 years ago [6-10]. Furthermore, his theory suggests that the survivors of the cataclysm handed over their knowledge required for their success, welfare and prosperity (astronomy etc.) to hunter gatherers all over the globe [6-10]. As a consequence, around 8000 to 6000 years ago, similar stone age architectures and iconographies developed all over the world, from Gobekli Tepe (Turkey) to Japan (Jomon culture), from 


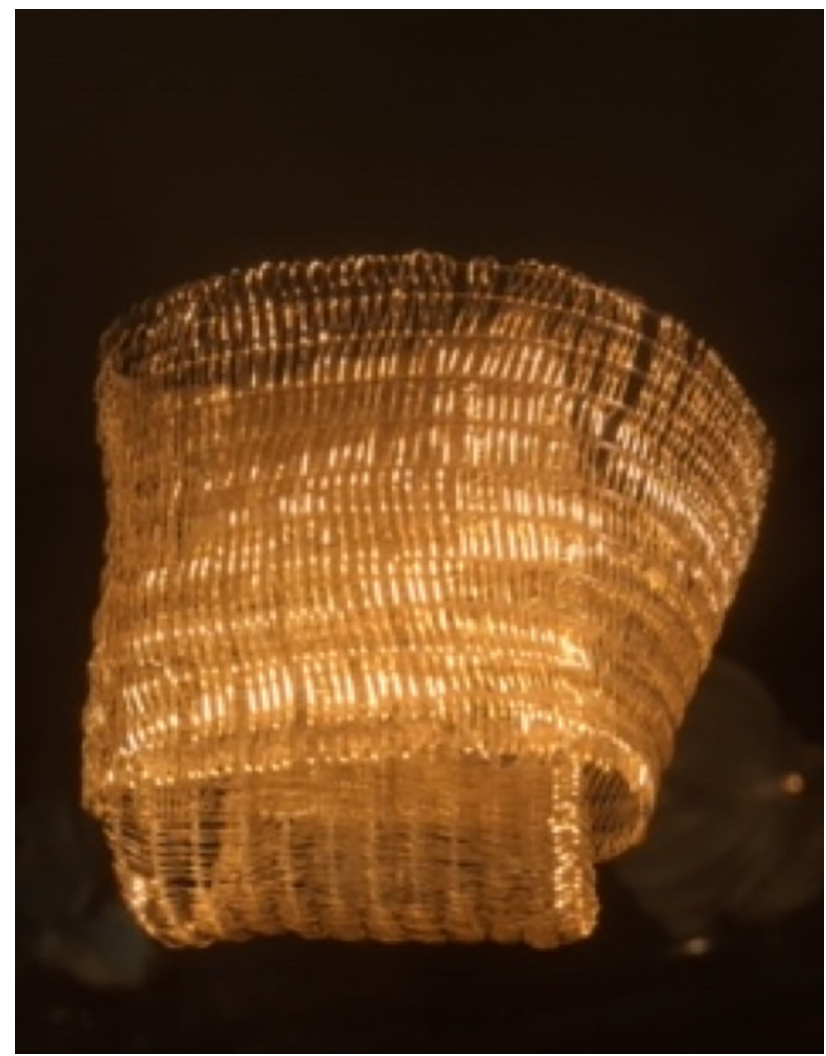

Fig. 3 The beautiful jewellery illustrates the idea that interwoven energetic fields make up the cosmos, as outlined in the text. Attached to the human body, these models allow us to enjoy collective memories and legacies of ancient cultures and civilisations. Image obtained at the Slavik Gallery, Downtown Vienna, Austria, EU

Mesopotamia to Egypt, from the Danube to the Indus and Mississippi valleys (Louisiana, Ohio, Alabama), from Mexico, Peru, Chile to Brazil, the Amazon, Easter Island, from Siberia to France, England and Portugal [6-10]. As such, Graham Hancock considers a common underlying cosmic code for the erection of these post-cataclysm structures: the henges, mounds, pyramids, sphinxes and temples are oriented towards the heavens and model precession, solstices, positions of the moon, planets (Venus, Mars) and stars (Orion) against the background of the Milky Way (the Afterworld) and the gates to the Underworld, as observed from the earth, i.e. the intersection points of the zodiacs and the milky way between the zodiac constellations of scorpion/sagittarius and taurus/gemini, respectively [6-10]. In addition, the ancient structures are suggested to "still image" and "freeze" the time of the cataclysm around 11,000 years ago, i.e. 9600 years before Solon's time, as depicted in Plato's Atlantis story. Thus, the structures are oriented according to the solstices and stellar constellations as they were visible from the earth around 11,000 years ago. Thus architecture "writes down" the collective memory of ancient legacies [6-10]. Recent studies published in Nature, Science, PNAS and other high-ranked peer review journals provide further support for this theory. The contributed data indicate that around 11,000 years ago the impact of a gigantic comet repeatedly hit the North American and Greenland ice sheet, segments of the comet faded out and spread over the Levante and Egypt [6-10]. Temples were erected there above the traces of the comet, including Gobekli Tepe, Harran, Baalbek, Jerusalem, Heliopolis, Gizeh and Mecca. And many of these spots are still in religious use today. Over the next 500-1000 years the impact of the comet elicited fundamental and cataclysmic environmental climate changes and an approximately 100 - to $150-\mathrm{m}$ rise in sea level, which subsequently spawned the eradication of this lost civilisation. Due to our inability to adequately understand the myths, we have been cut off from (the possibility to consider) the legacy and knowledge from this lost civilisation. The example nicely illustrates what happens if lost codes are rediscovered and allow us to revisit hidden stories, memories, knowledge and understanding (Fig. 3). The same may be true in medicine.

Let us have a look at a speciality of medical science that nicely teaches us about the relations between codes, myth (symptoms, signs), surgery and science. Oncology shines brightly, shares holders greatly and teaches a very good example that demonstrates what happens if the code for the adequate translation of symptoms and signs gets lost. The vascular system and/or the inner and outer skins and surfaces of the human body may get involved in a cancer-mediated immune stress response, which orchestrates a socalled para-neoplastic manifestation [11-13]. Thus the underlying cancer (colon, lung, breast, prostate, kidney-cell cancer) provokes dermatitis, enteritis, thrombosis etc. Therefore, it is essential for medical teaching and education to foster awareness of this type of cancer-induced phenomena [11-13]. Otherwise, the lack of code and inability to adequately read the symptoms and signs may have major consequences for patients. In contrast to this, knowing the code and retrieving this fundamental clinical information fosters cancer diagnosis at an earlier stage, thereby contributing to improved survival, quality of life and well-being. Taken together, medical teaching and education should involve meticulous code-learning (legacy) for the adequate reading of symptoms and signs (culture) [14].

\section{Leading opinion, ruling opinion, and groupthink}

Conceptually life models a fascinating multi-semiotic stream of perceptions, which presents in the form of tentative changes, alterations, oscillations, modifications and innovations. As a consequence, what is held for state of the art may soon be regarded as old-fashioned and inappropriate. In contrast, homo sapiens loves stability, security and prefers to stick to used habits and customs. Changes and alterations tend to foster vague perceptions of insecurity. It is harder to 
develop and design a new trail than it is to follow a secure path of well-prepared, known and long-lived fashions, habits and customs. Therefore, the large majority of a given population, i.e. approximately $99 \%$ of women and men, fear abrupt changes and alterations of the mindset, knowledge and opinion. Therefore, they resist rapid changes and alterations of opinions. Furthermore, their lives do not allow them to find the time analyse a matter, the facts and knowledge in depth. But most of all this is not always their fault. They are forced to focus their energies and attention on obtaining money, care for their families, education for their children and thus are more or less forced to follow a superficial mindset. As a consequence, they are not allowed to foster a deep understanding of their world and the tensions of social, economic, industrial and power game interests. Thus, lack of time leads them to follow the prevailing opinion. Furthermore, the prevailing opinion itself closes the gap as it serves to secure and justify a given knowledge, save it from being changed and prevent alterations, which in turn would foster insecurity and, most importantly, loss of political POWER. Moreover, those serving the ruling opinion fear getting wiped out, losing their jobs and their acceptance and their respect, and their political POWER, influence and importance, indeed their status, if novel ideas, concepts and mindsets arose, got accepted and replaced the prevailing opinion. Thus, there is considerable and fundamental resistance to new ideas, concepts and mindsets that oppose the ruling opinion. As a matter of fact, the ruling opinion does not rule, since it teaches the truth. The ruling opinion rules, since it gained the POWER to be taken for granted by the majority, those $99 \%$ of the population. As such, history (! the manifestation of groupthink!) has neglected and opposed the idea of a lost civilisation, as suggested above. However, over time, when data in favour of the new theory accumulate, the ruling opinion has to undergo a critical review and allow a consideration of new concepts, models and strategies. As such, an important chapter of our history may need to be revised and allow the possibility of a lost Ice Age civilisation, which was wiped out due to the consequences of a cataclysm induced by the impact of a comet 11,000 years ago. Most interestingly, our collective memory incorporated multiple traces of this event, including the legacies of ancient teachings, educations, storytelling and myth. Since the ruling opinion is now altering in favour of the awareness of these facts, future studies will enrich our understanding of this important epoch of our history. Furthermore, the example demonstrates the consequences of an uncritical belief in the so-called ruling opinion. In the recent issue of European Surgery we summarised the political, social, historical and philosophical consequences of blind succession of the ruling opinion and groupthink. The same may be true in medicine. Therefore, let us see the impact of uncritical groupthink on the management of gastroesophageal reflux disease (GERD) and Barrett's oesophagus [1-5]. This story perfectly parallels the theory of the lost civilisation [6-10], where the fascinating dome of records within the mucosa of the lower end of the oesophagus starts to tell a fascinating history of ourselves [1-5].

As surgeons you routinely perform gastroscopies. During gastroscopy you may ask: where does the oesophagus end and at which level does the stomach start? You may ask these questions since awareness of the endoscopic anatomy is essential for adequate diagnosis (classification of a disease, tumour, polyp, inflammation) and treatment (swallow, cut, balloon, radiate, stent, dilate, fade out?). It may matter if you have to treat a disease of the stomach vs. a disease of the oesophagus, to treat cancer of the stomach vs. cancer of the oesophagus [1-5]. Given the possibility of misinterpretation and false classification, you may treat (resect) the wrong (innocent) organ. That is to say, you may wrongly resect the stomach for the treatment of cancer of the distal lower end of the oesophagus (and leave the diseased remnant of the oesophagus in place), or you may block gastric acid secretion for the treatment of a mechanical failure of the lower oesophagus [1-5]. Interestingly, the routinely used term "gastroscopy" leaves out the name of the organ, which deserves major and focused attention and harbours the most frequent reason for the test: the oesophagus, the gullet, the tube-sacked carrier of the food, which is affected by the consequences of GERD (ancestor-reflux disease) and Barrett's oesophagus (BE) [1-5]. While the majority of physicians have followed the ruling opinion and groupthink mindset over the last 30 years (administer proton pump inhibitor [PPI] therapy to inhibit gastric acid secretion), the frequency of reflux-induced oesophageal cancer dramatically increased in Europe and abroad [1-5]. Thus it seems to be evident: the groupthink model lacks adequate understanding of the cause of GERD and BE. The acid is not the cause of GERD and BE. Reflux is not the cause of GERD and BE. As outlined by Para Chandrasoma and Tom DeMeester, the only cause of GERD and BE is the failure of the function of the lower oesophageal sphincter and the incorrect geometrical anchorage of the lower end of the oesophagus within the diaphragm [1-5]. It took more than 25 years for the work of Para Chandrasoma and Tom DeMeester to start to gain a feel, a spirit, a tiny little breath of acceptance in the large mass of copycats, hangers-on and free riders, who still live, freeze, count and wait within the "us and them" dark side of the moon [15]. Taken together, there is a tendency in our societies for most individuals to uncritically follow the groupthink (the "truth"!) and thus create a process which is outlined, interpreted, thought, taught, referenced, presented and remembered as history [14, 15]. It is easier, safer and definitely faster to rise up the job ladder if one follows the groupthink than to reach out for new, as yet unexplored continents. Thus, being is thinking (Parmenides) and equals uncritical 
groupthink times opinions minus the small portion of critical opposition (Sir Karl Popper's verification and falsification) and thus creates the state of affairs summarised in the form of history (cui bono?). Outbalanced, critical, anti-mainstream reasoning fosters the discovery of new ideas, models, concepts and knowledge. But, most importantly, we must admit that not all we serve and choose as truth is bad. During your daily surgical routine you are continuously producing numerous advantages, possibilities and creative outlooks for yourself as well as others, i.e. your cocollectors and colleagues. If you share humility and passion you may await how new concepts will withstand the test of time. If we honestly continue to apply the concepts that have been shown to withstand the test of time, we share the opportunity to maintain and secure treasures for the benefit, innovation, progress and prosperity of our civilisation (science, medicine, oncology, technology, etc.). As such, there is huge scope to fundamentally trust in the future. Surgery can improve the quality of life and well-being of patients. And here we are aware of the fact that it becomes essential to differentiate between reality, truth and atmosphere. Criticism nourishes the soil for the fruitful products of our mind.

\section{Echoes from the universe}

Conceptually, the sum of our perceptions creates our reality (Fig. 4). Furthermore, the actual, momentary meaning, interpretation and significance of this reality for a given person describes the truth: the individual state of mood, temper and atmosphere (Fig. 4). From here our reasoning nourishes the soil for our mindset and the interpretation of our world. In line with this notion, the absolute truth aims to describe the very essence of our existence: the invariance of being borrowed and finite.

Finally, it turns out that man cannot stand to find him- or herself exposed to this fundamental truth. What are the qualities of this truth? Colour, smell, sound, tension, force, stretch, laughter, crying, wheezing, coughing, burning, temperature, speed, change, alteration, orientation, polarity, manifestation, invariance? Man is not allowed to know that. YOU and me are not allowed to borrow any information on the qualities of this essential, fundamental truth. Therefore, YOU and me continuously follow two approaches to deal with this truth: either to illustrate a model of the model (heaven, earth, hell etc.) or to echo away in the form of knowledge: we turn away from this truth and act instead, we turn away and try to compensate. It seems clear: man does not know how to deal with this truth, how to handle and process these types of issues, facts, qualities and behaviours. Therefore, man diverts her or his attention away from this very truth and becomes highly creative ([16]; Fig. 5). Man involves him- or herself to bridge his or her existence and invents stories and myths about time, space, atoms, particles, waves, fields, forces, circuits, melodies, colours, structures, speeds, lights, systems, gods, religions, politics, sciences, arts, computers, cell phones, tablets and the poly-semiotic performance of oncology, women, men, children, nuts and shells ([12-16]; Fig. 5). Echoes of our past are continuously arriving to us from the universe,
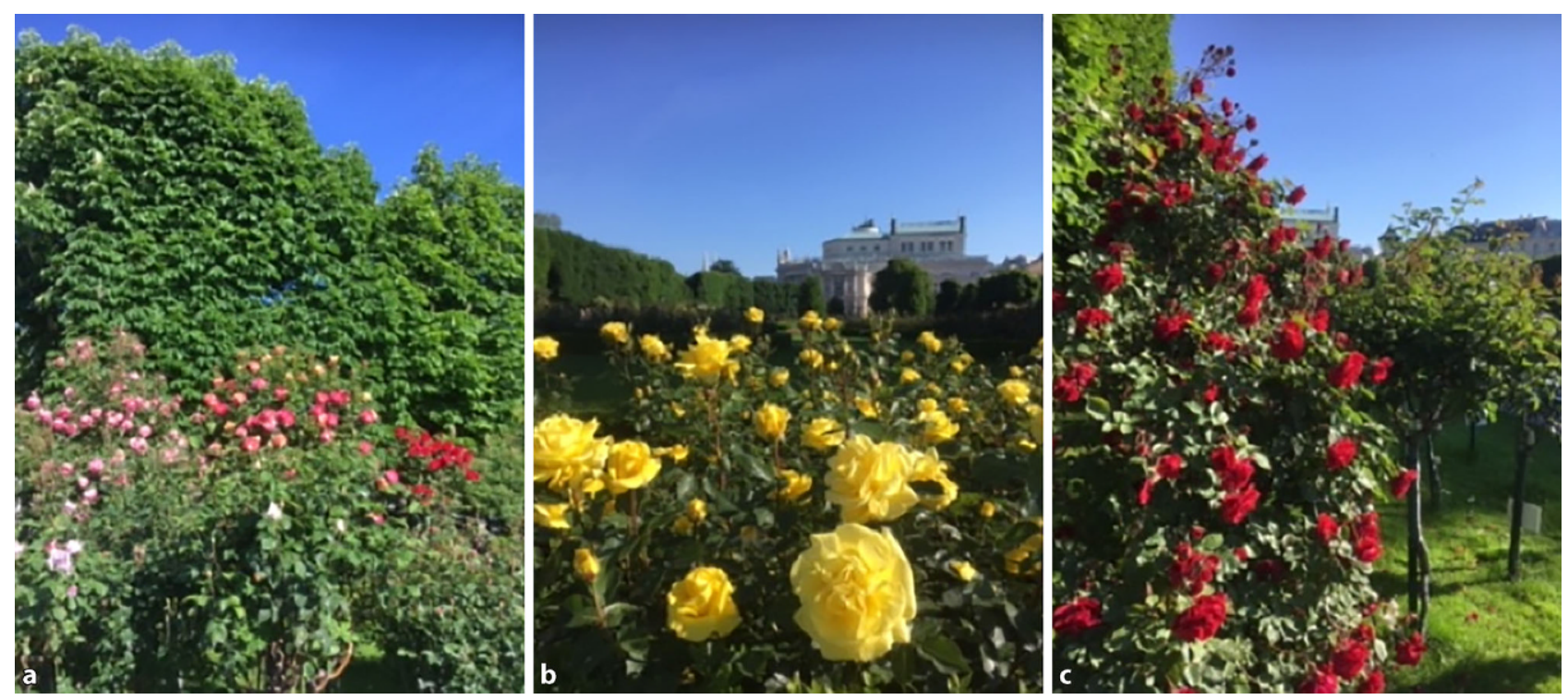

Fig. 4 The images $(\mathbf{a}-\mathbf{c})$ illustrate the author's idea that reality is the sum of perceptions obtained by an individual. The meaning of the perceptions echoes the truth and this equals the momentary state of mood, temper and atmosphere, as presented, for example, in the "white house" (rear of panel b) performances at the Imperial Court Theatre, Vienna (Heldenplatz, Hamlet, Faust etc.). Images obtained mid-May 2019 in the People's Garden, Vienna, Austria, EU, world, solar system, milky way 


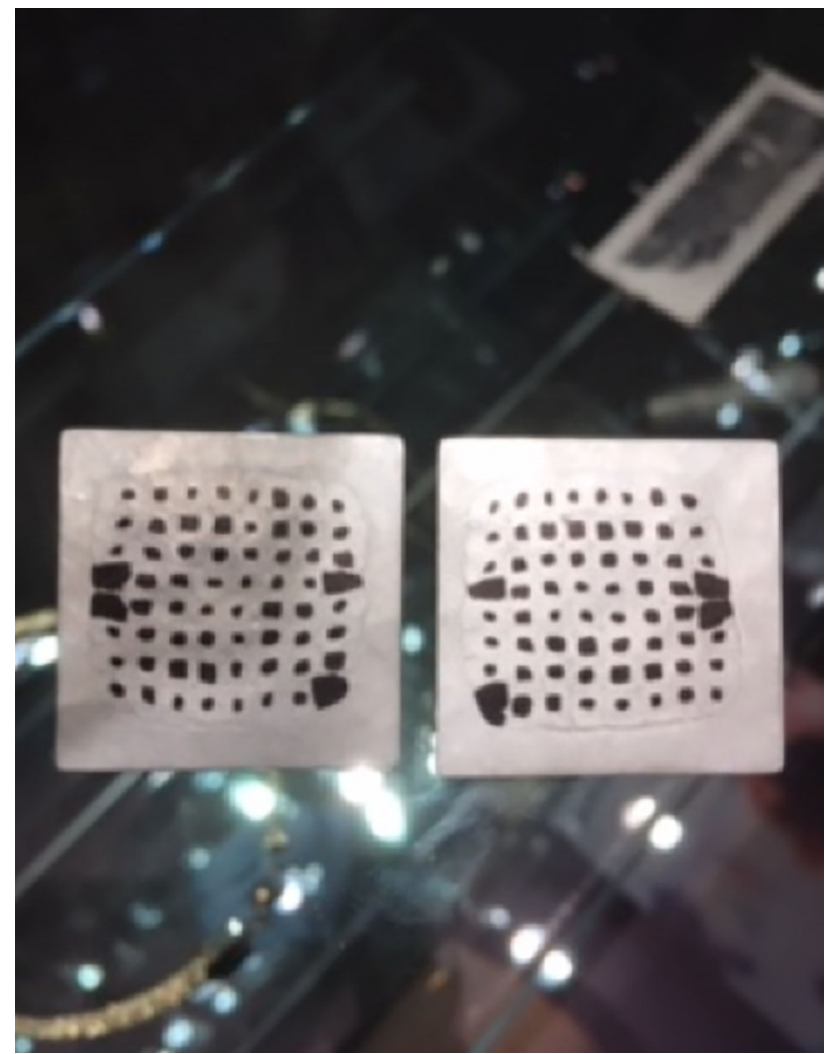

Fig. 5 The jewellery mirrors the idea that the matrix of the universe involves the interaction of four fields: the space/time, electromagnetic, weak and strong nuclear power field. This model teaches the modern science/myth of mankind the explanation of the world, as outlined in the text. Image obtained at the Slavik Gallery, Downtown Vienna, Austria, EU

unheard, unseen, unexpected. Reach out for those echoes. These stories definitely contribute and help to illustrate the world and serve a better understanding of the echoes from the universe (Fig. 5). As such, these stories aim to translate our existence into treatable signs. We listen, learn, teach and become a take away, over-the-counter marble stone, drive in and through and over and around to be a boiler for all industries and economic interests, share-holder confidence and master plans. You, dear reader, mirror the mill of emotions and atmospheres. DID YOU GET THE MESSAGE? Taken together, once upon a time there was a curious flame and this flame created our thoughts beyond time, space and understanding. It all became atmosphere, temper, emotion and MIND ([14-16]; Fig. 1, 2, 3 and 5). Once upon a time you felt safe within the well-protected childhood world of fairy tales, stories and ferry-boat fables, where the moon kisses the stars and the sun mingles with the leaves of a tree, the eyes of a bird and the bloom of a flower. As such, you, dear reader, were well prepared for that part of the world, which continuously tunes in all humans, all beings, all living energies of the universe: need for love, respect, understanding and fairness [15, 16]. Require desire and be YOU. Stay tuned and echo the galaxies.

Martin Riegler

Acknowledgements The author thanks music for helping him to become in-tune with the fundamental streams of emotions needed to create the waves of mood, temper and atmosphere; he is also grateful for being allowed to borrow the sensations required for better disease management and to increase the understanding of the mechanisms underlying the development, appearance and disappearance of disorders that impair the well-being, productivity and health of human beings. The author also thanks his FAMILY, FRIENDS and SUPPORTERS (no author is an island), without whom these ongoing projects could not be sustained and reach the minds of the readers, thinkers, watchers and copycats. And thus, the author does not cease to be convinced that openminded surgeons do in fact exist and he will not give up critically reviewing the leading groupthink-trapped opinions in the fields of medicine and abroad.

Conflict of interest M. Riegler declares that he has no competing interests.

\section{References}

1. Lenglinger J, Eisler M, WrbaF, etal. Update: histopathologybased definition of gastroesophageal reflux disease and Barrett's oesophagus. Eur Surg. 2008;40(4):165-75.

2. Chandrasoma PT. Histologic definition and diagnosis of epithelial types in the oesophagus and stomach. In: Chandrasoma PT, editor. Diagnostic Atlas of gastroesophageal reflux disease; a new histopathology-based method. London: Academic Press; 2007. pp. 61-91.

3. Chandrasoma PT. Progression of GERD at the clinical level. In: Chandrasoma PT, editor. GERD; a new understanding. London: Academic Press;2018. pp.391-456.

4. Chandrasoma PT. Progression of GERD from the perspective of LES damage. In: Chandrasoma PT, editor. GERD; a new understanding. London: Academic Press; 2018. pp. 479-501.

5. Chandrasoma PT. New pathologic test of LES damage. In: Chandrasoma PT, editor. GERD; a new understanding. London: Academic Press; 2018. pp. 503-25.

6. Hancock G. A truly cataclysmic period. In: Hancock G, editor. Magicians of the gods. London: Coronet; 2015. pp.36-9.

7. Hancock G. Rebirth. In: Hancock G, editor. Magicians of the gods. London: Coronet; 2015. pp. 438-40.

8. Hancock G. Where heaven and earth met. In: Hancock G, editor. America before. New York: St. Martin's press; 2019. pp. 17-20.

9. Hancock G. Ghost cities of the amazon. In: Hancock G, editor. America before. New York: St. Martin's press; 2019. pp. 137-50.

10. Hancock G. Earth island, sky world. In: Hancock G, editor. America before. New York: St. Martin's press; 2019. pp. 239-43.

11. Rassy EI, Assi T, Kattan J, Pavlidis N. Paraneoplastic syndromes in cancers of unknown primary: an unknownn field for oncologists. Bull Cancer. 2019; https://doi.org/10.1016/ j.bulcan.2019.03.011.

12. Henry K. Paraneoplastic syndromes: definitions, classification, pathophysiology and principles of treatment. Semin 


\section{editorial}

Diagn Pathol. 2019; https:// doi.org/10.1053/j.semdp.2019. 01.002.

13. Brown R, Ginsberg L. POEMS syndrome: clinical update. J Neurol. 2019;266(1):268-77. https://doi.org/10.1007/ s00415-018-9110-6.

14. Krupenye C, Call J. Theory of mind in animals: current and future directions. Wiley Interdiscip Rev Cogn Sci. 2019; https://doi.org/10.1002/wcs.1503.

15. Dogan A, Morishima Y, HeiseF, et al. Prefrontal connections expressindividual differencesinintrinsic resistance to trad- ing off honesty values against economic benefits. Sci Rep. 2016;20(6):33263. https://doi.org/10.1038/srep33263.

16. Rovelli C. Anaximander's contributions. In: Rovelli C, editor. Anaximander. Yardley: Westholme Publishing; 2007. pp.29-36.

Publisher's Note Springer Nature remains neutral with regard to jurisdictional claims in published maps and institutional affiliations. 